\title{
Retour sur « La queue qui remue le chien »
}

\section{Paul Jorion}

\section{OpenEdition}

Journals

Édition électronique

URL : https://journals.openedition.org/tc/5149

DOI : $10.4000 /$ tc. 5149

ISSN : 1952-420X

\section{Éditeur}

Éditions de l'EHESS

\section{Édition imprimée}

Date de publication : 30 juin 2010

Pagination : 670-672

ISSN : 0248-6016

\section{Référence électronique}

Paul Jorion, « Retour sur « La queue qui remue le chien » », Techniques \& Culture [En ligne], 54-55 |

2010, mis en ligne le 30 juin 2013, consulté le 29 septembre 2022. URL : http://

journals.openedition.org/tc/5149; DOI : https://doi.org/10.4000/tc.5149 


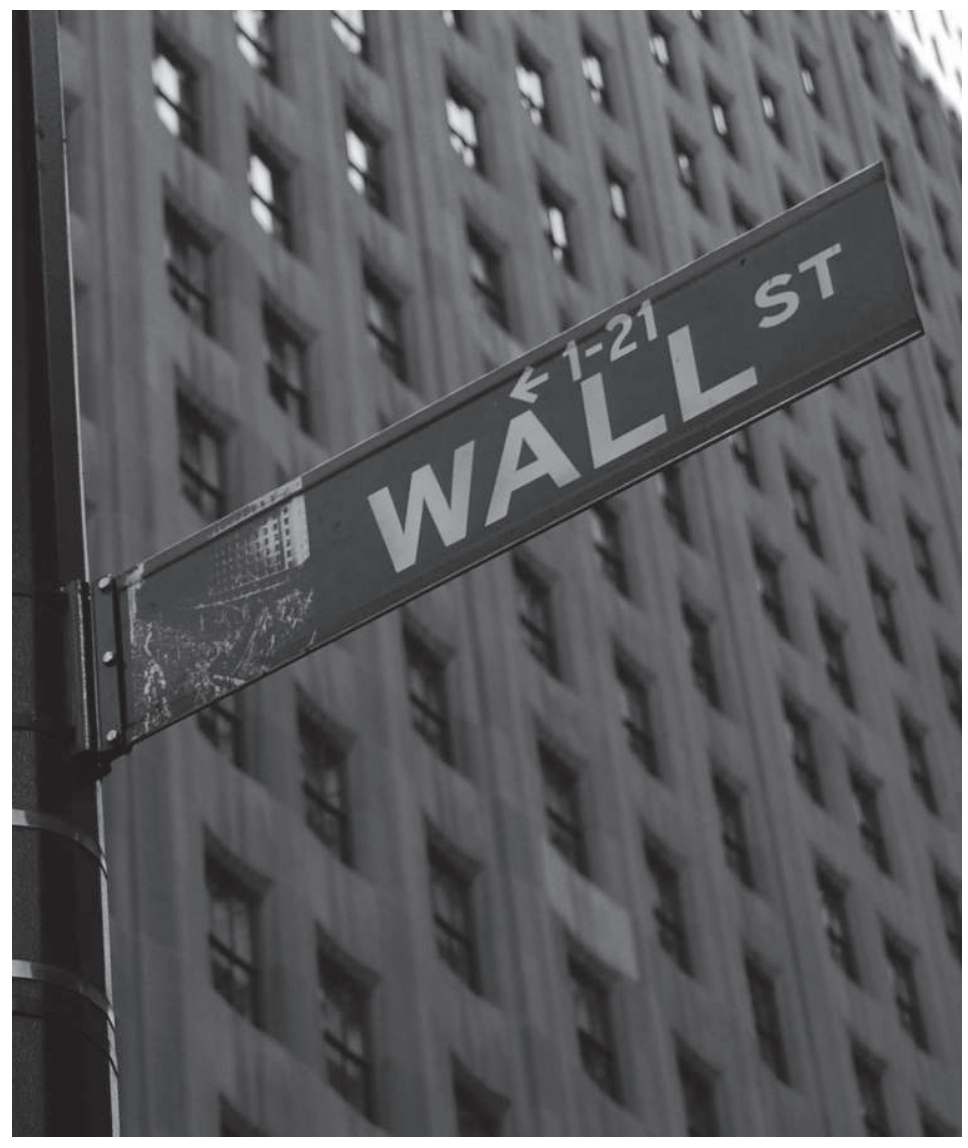




\section{"La queue qui remue le chien »}

La première chose qui me frappe à la relecture de ce texte rédigé il y a dix-sept ans, c'est son actualité. On a tendance bien sûr quand les marchés boursiers s'effondrent en 2000, dans la crise des "start-up», à chercher à cette crise des causes dans les événements qui l'ont immédiatement précédée, comme la popularisation de l'Internet ou les modifications dans les règles comptables, qui permettent désormais d'inclure dans les bénéfices des gains futurs hypothétiques. De même, quand j'écris en 2004-2005, La crise du capitalisme américain ${ }^{1}$, qui ne sera pas publié avant janvier 2007, je peins un vaste panorama des éléments qui contribuent au déclenchement de cette crise mais la «préhistoire » de ces facteurs contributifs ne couvre pas davantage que les cinq années qui précèdent. Et pourtant!

Et pourtant, tout se trouve déjà là dans ce texte de 1994 qui brosse le portrait d'une époque où les effets de l'informatisation viennent se mêler aux pratiques antérieures, quand la finance se faisait encore «à la main »: de la bombe à retardement que constitue l'interconnexion des marchés à terme aux marchés au comptant, jusqu'aux titres adossés à des crédits hypothécaires américains, les fameuses Mortgage-backed securities qui seront au centre de la crise des subprimes. Et ceci attire l'attention sur l'actualité de l'objet-même de l'article: les changements qualitatifs de la finance que l'informatisation a apportés avec elle.

La vitesse de l'ordinateur joue bien sûr un rôle qui, comme l'article le met en évidence, marque chez les opérateurs, les traders, la fin de la compréhension intuitive du fonctionnement des marchés. La complexité ensuite, masquée partiellement par la capacité qui s'accroît parallèlement de valoriser des produits de plus en plus sophistiqués. Le krach boursier de 1987 est causé par la complexité de marchés interconnectés, où « interconnexion » signifie aussi, comme on le découvre dans la douleur, risque de 
contagion démultiplié. La crise obligataire de 1994 est provoquée elle par l'incapacité de gérer encore le risque par des stratégies de couverture dans des marchés où les réactions « non-linéaires » abondent désormais, du fait de leur plus grande complexité. La montée des taux d'intérêt que cette crise entraîne comme une conséquence inattendue du débouclage de positions de couverture inefficaces, apporte la dévastation dans l'économie réelle, dont on découvre pour la première fois qu'elle est devenue « le chien qu'agite la queue » de la finance. Dernier élément enfin: la délégation des décisions à la machine fait que même si la peur de la catastrophe croît chez les opérateurs, l'ordinateur qui est désormais en charge des opérations ne connaît pas lui la crainte, et le risque de pertes s'en trouve ainsi démultiplié.

La catastrophe de 2008 sera à la mesure de la montée des périls qui, comme la lecture a posteriori de l'article le révèle de manière dérangeante, était déjà en gestation en 1994. 